\title{
The Role of the Textbook in EAP Writing Research
}

\author{
John M. Swales
}

\begin{abstract}
This paper reviews the potential role of writing textbooks in increasing our understanding of academic writing. It argues that this role is underappreciated for several reasons. These include the dampening effects of existing discoursal and social-constructionist accounts of introductory college textbooks, a reluctance to look beyond the ostensible student audience, and a diffidence in recognizing textbook author motives other than the "commercial" or the "ideological." The paper then discusses a recently completed textbook as a means of showing how a complex set of motives can result in some contribution to research and scholarship. The paper concludes by arguing that textbooks should not be automatically excluded from the set of research-process genres since they may consolidate and apply recent scholarship, incorporate new research findings, and generate interesting new topics worth further study. In effect, advanced textbooks are important hybrid genres.
\end{abstract}

\section{The Textbook as Genre}

In the first part of this paper, I would like to re-assess the textbook as a component of the system of genres (Bazerman 1992; Swales 1993b) which orchestrates our academic life and verbal behavior. This re-assessment falls into three parts: a brief review of studies of textbooks themselves; a reconsideration of the audience design of textbooks; and an exploration of the complex set of motives that may impel academics to embark on textbook writing. I will argue - at least in the fields that I know something of, such as ESP, ESL, and composition - that complexities in reader-author textbook relationships have been consistently under-appreciated, even if for understandable reasons. In consequence, the textbook is typically assigned a marginal and controversial place in the academic genre-system, particularly in terms of the improbability and implausibility of it contributing to our communal research enterprise. In the second half of the paper, I argue for a reconsideration of the textbook as a potential contributor to EAP writing research. Most of the illustrative material is drawn from a case-history of a recent EAP writing textbook which I have co-authored.

\section{Textbooks as Texts}

Studies of textbook discourse have so far been largely restricted to introductory texts in standard undergraduate fields such as physics (Kuhn 1970), 
genetics (Mycrs 1992), gcology (Lovc 1991, 1993), and economics (Henderson \& Hewings 1990; McCloskey 1985; Tadros 1985). These studies provide us with useful insights into a wide range of textbook characteristics: their organization (e.g., Love 1991); the contractual nature of the author-student reader bond (e.g., Tadros 1985); the paucity of hedging, the diminution of human agency, and the use of abstract nominalization as subjects of processes (e.g., Hewings 1990; Love 1993; Myers 1992); the deployment of prevailing metaphors (e.g., Mason 1990); and the mediation and the marketing of difficult material (e.g., Swales 1993a; Tadros 1985). With few exceptions, this research strongly underscores a Kuhnian perspective: standard introductory textbooks are rarely little more than conservative encapsulations of prevailing paradigms. Appearance, arrangement, certitude, and style come together to make them prime examples of what Brown (1993) neatly calls "canonizing discourse."

Indeed, many researchers offer some contrast between the "primary" genres of papers and research articles and "secondary" ones of textbooks and lectures. Myers (1992) does this most explicitly: he argues "authors of textbooks try to arrange currently accepted knowledge into a coherent whole, whereas authors of journal articles try to make the strongest possible claim for which they can get agreement" (1992: 8). Later on in the paper, he goes on to dichotomize differences in readership as follows:

The reader of the article:

- sorts oul the new knowledge from the old

- attributes credit to researchers

- assesses the certainty of statements

- infers cohesive links between knowledge

- traces the relations to other texts

- evaluates the illustrations ${ }^{1}$

On the other hand, the reader of the texthonk:

- arranges facts in order

- separates facts from researchers

- takes most knowledge as accepted

- infers knowledge using cohesive links

- uses the array of sections in the book

- uses illustrations to clarify the text. (1992: 13)

Two questions arise from this brief survey. The first is whether the described amounts of textbooks are indicative of textbooks in general, or only applicable to the narrow range of textbooks so far investigated. This question will be held over until the conclusion. The second is whether Myers' dichotomy, however useful and pointed, adequately captures the full story of textbook readership; this question will be addressed in the next section.

\footnotetext{
'In fact, in an earlier 1989 paper, Myers argues for a distinction between a readership that is "involved in the ongoing research problem" and one "that takes an interest in some of the research findings" (1989: 3 ). Interestingly. I shall argue for a comparable differentiation in the textbook audience.
} 


\section{Textbooks and their Readers}

The editorial of the December 1993 issue of College Composition and Communication is entitled "Scholarship, Promotion and Tenure in Composition Studies." In it, editor Gebhardt describes six ways of viewing scholarship in composition, one of which is to examine the "genre of publication." He lists the following genres, in the following order:

Scholarly book

Refereed article

Book chapter

Non-refereed article

Textbook. (Gebhardt 1993: 440)

In this area then, at least on the surface, the textbook seems something more than a Kuhnian object, since it does indeed find a role in scholarship. Even so, despite its size and the sustained effort that has presumably gone into its creation, the textbook hangs nervously and tenuously in last place. Reasons for this timid placement are, of course, not hard to find. As Geertz (1983) would have it, in the fields in which we work, the textbook is a "blurred genre": a miscegenation of scholarly fish and commercial fowl.

Arguments against a Kuhnian view of textbooks in our fields (i.e., as mere conservative encapsulations of prevailing paradigms) are not uncommon. Here, for example, is a fervent appeal from an official committee of the Modern Language Association:

\footnotetext{
Composition research is often disseminated in the form of textbooks, used in writing classes at various levels. While in other disciplines and even in other areas of our own discipline this form of scholarship is highly derivative of the scholarship that alters the field, textbooks for composition specialists frequently constitute a primary way of communicating the results of extensive research. We therefore recommend that departments consider composition textbooks as the equivalent of other scholarly books, measurable like other scholarly books according to rigorous intellectual standards. (cited in Gebhardt 1993: 442)
}

Unfortunately, my own university, for one, tends not to accept this argument, even if it may make exceptions for "advanced" textbooks in established scholarly fields such as Philosophy or Linguistics. Academics, the university believes, should not be rewarded a second time for "commercial ventures" through promotions and pay-raises. Against this view, Alred and Thelen (1993) trenchantly observe:

\footnotetext{
Whatever an author's motivation, the notion that textbooks are somehow disreputable because they may earn profits for authors is simply bogus. It denies that academics receive royalties from traditional scholarly books, stipends from invited lectures and professional reviews, salary increases from job offers by competing institutions, and so on. (Alred \& Thelen 1993: 467)
}

Since even a small textbook requires literally hundreds of hours for its completion, in our field other kinds of enterprising "extramural" activity, such as 
consultancy, offer a clear advantage in terms of monetary return for effort expended. While it is undoubtedly true that a handful of people in EFL/ESL or Composition have become wealthy from textbooks, it is neither logical nor fair to ascribe to the many, the commercial success - and hence the commercial motivation? - of those few. Much of most textbook authors' motivations seems to lie elsewhere.

Clear evidence for a more complex set of motives emerges when we reconsider the audience of the textbook genre. Of course, publishers (and their authors) devote considerable energy to providing an attractive cover and layout and to making the material "transparent" to the students. Further, the students, as consumer-readers, are often directly addressed as "you" indeed, the studies summarized in the previous section depict a whole bundle of strategies aimed at making intellectual material as accessible as possible.

However, "both publishers and authors are well aware that while the composition textbook is directly addressed to the student audience, the textbook is constructed for the professional audience" (my emphases, Alred \& Thelen 1993: 469). Indeed, in all but exceptional circumstances, students only become readers of textbooks after they have been instructed to study them. It is we professionals who evaluate manuscripts, write reviews, peruse catalogues, visit book exhibits, recommend adoptions, and orchestrate the use of textbooks in classes. It is not the students who do these things, however much we may value the different kind of feedback students may provide. Textbook authoring is thus - and despite appearances to the contrary - more dialogic (cf. Bakhtin 1986) with the evaluator-reader than with the consumer-reader. It is our colleagues' opinions and decisions that we value and attempt to influence. Although sales are certainly one factor in how we assess the reception of the textbook, as instructors we also hanker after succes d'estim.

At least for those of us who hold academic positions or who are not full-time textbook writers, the student audience of textbooks can then best be seen as a rhetorically machined over-simplification. But, alas, this deceptively simple orientation seems highly successful. How else can be explain the fact that textbooks are often thought of by our colleagues as "potboilers" even when they are not? How else can we explain the fact that the standards for reviewing textbooks, and the amount of space they garner in review sections of journals, are abysmally low? How else can we explain the fact - despite MLA and other protests to the contrary - that any expectations we may have that a textbook will contain any primary research are equally low? How else can we explain, especially in ESP, that well-established rejectionist stance towards textbooks even as teaching aids (Swales 1990) - that assumption "that the truly professional practitioner uses locally-produced or in-house materials for teaching, not published textbooks" (Robinson 1991: 56)?

We can only do so, it would seem, by assuming that textbook authoring as professional dialogue with the target discourse community has failed. Some part of the reason must lie in the context of the professional colleague as evaluator having to read "between the lines" rather than being directly addressed. Indeed, as we have seen in the two-way contrast established by 
Myers (1992), the evaluator-reader tends to get written out of accounts of the textbook audience. However, if we leave aside the problematic nature of "knowledge" in pedagogical fields, we cannot help but be struck as professional readers by how closely our reading matches Myers' article reading and how little it has in common with student textbook reading. Certainly, the professional reader of a textbook in our fields, amongst other things ${ }^{2}$ :

- sorts out the new knowledge from the old,

- assesses the certainty of statements,

- infers cohesive links between knowledge,

- traces the relations to other texts,

- evaluates illustrations.

And yet we seem not to adequately recognize this kind of reflective reading, or at least, not to adequately acknowledge it. Like Myers, we tend to perceive a dyad and not a triad of author, evaluator, and consumer.

Of course, some part of this dialogic failure can also be ascribed to the undoubted truth that by no means do all textbooks have something new or important to communicate. But the fact that some textbooks are not worth entering into dialogue with does not mean that none are worth the attention we traditionally give to research papers and scholarly accounts. Further inhibiting factors may be publishers' efforts to limit the amount of radical innovation or to make unwarranted claims for their products. But not all the dialogic failure can or should be explained away in these guises. There remains some uncomfortable residue that will not go away, as starkly evidenced in, for example, the continuing proportional decline in citations to textbooks in TESOL Quarterly (Swales 1988) and in College Composition and Communication (Phillips, Greenberg, \& Gibson 1993). ${ }^{3}$

So far I have outlined what I perceive to be a problem. In essence, that problem resides in the traditionally diminished place assigned to textbooks as a class in the systems of genres that moderate our fields, whether they be composition, ESP, or ESL - all fields ironically wherc campaigns for textbook recognition have been particularly vigorous. My partial and precarious solution is to discuss a recent textbook in terms of its possible contribution to knowledge in the area of academic writing. The case is discussed not to extoll the virtues of the materials themselves, not indeed to publicize them, but rather to bring to the surface the complex interplay of scholarship, personal research,

\footnotetext{
${ }^{2}$ Amongst those other things would be how well a textbonk matches an instructor's own views on how particular material or how a particular skill should be taught. A full account would also include that special kind of reading that instructors employ when reading a textbook in preparation for class.

${ }^{3}$ It is unclear whether graduate or teacher education should also share some responsibility for the diminution of textbooks as citable resources. On the one hand, in most classes critical discussion tends to focus on scholarly books and research articles. On the other, most Masters programs have a course that deals with the analysis and use of published teaching materials. Perhaps the problem is exacerbated by such splits between "theory" and "practice."
} 
teaching experience, course design, and individual belief that led to their creation. However, as a final preliminary, we first need to reflect a little further on the complex motives that may drive textbook writers to undertake their arduous tasks.

\section{Textbooks and their Motivations}

So, let us turn in greater detail to the question of textbook authors' motivations, especially as now placed against a general background of trying to influence their peers. The answer to this question is, I suspect, surprisingly and interestingly complex. Here are six possible components for authors of writing textbooks:

1. to pluralize successful and interesting writing activities developed in singular classrooms;

2. to disseminate a vision (or theory or ideology) about the nature of the writing process and how it can be fostered;

3. to demonstrate how a body of knowledge about language or discourse or society can be put to applied use;

4. to combine linguistic, rhetorical and methodological investigations in a genre that easily encompasses all three;

5. to gain prestige and visibility within the chosen discourse community, particularly as an "all-rounder";

6. to respond to a perceived gap in the market, either as an individual initiative or as a commissioned work (and doubtless to profit from the filling of that gap).

We have here, then, six roles for the textbook author: (1) the talented teacher, (2) the advocate, (3) the applied linguist, (4) the master/mistress of all trades, (5) the career-builder, and (6) the canny marketeers. These roles, I believe, are more likely to be conjunct than disjunct, especially for those of us who see textbook writing as a small "para-career" rather than a principal occupation (Swales, in press). More importantly, I would argue that these motives (and perhaps even others) aggregate as experience and reputation grow. My first textbook, Writing Scientific English (1971), was, for example, motivated almost entirely by (3), perhaps because I had recently spent a year studying Applied Linguistics in graduate school. Since then, the motives have become more complex and, by the beginning of 1993, when Christine Feak and I started serious work on Academic Writing for Graduate Students, I was influenced, to lesser and greater degrees, by all six motivations. On the other hand, for Chris Feak, co-authoring her first textbook, the motives were primarily three: to demonstrate her classroom and materials expertize (1), "to help clcvate the overall lcvel of understanding of what academic writing is" (a kind of (2)), and to gain some visibility (5) in an increasingly competitive profession with relatively few regular and adequately rewarded positions. 


\section{The Evolution of a Textbook}

The work that I shall use as a matrix for assessing textbook contributions to research is entitled "Academic Writing for Graduate Students: Essential Tasks and Skills" (Swales \& Feak 1994). As the title indicates, we have excluded non-native speaker (NNS) undergraduates from our plans. We think the undergraduate market in the U.S. is already well supplied with Writing and Reading-Writing textbooks. In other words, we see no real opportunity for the canny marketeer here. Further, our experience suggests that NNS undergraduates and (post)graduates come to English writing with different strengths and weaknesses and have different demands placed upon them. Enrolled undergraduates are typically encouraged to write in a range of styles (not excluding "developing their individual voice"), for a range of disciplinary contexts. They are often short of ideas as to what to write about and typically need help with topic development and with finding and using sources of information.

Graduate students have largely the opposite profile. They are required to write academically and in a typically formal style within a fairly narrow compass of disciplinary areas. They are typically capable of analysis and logical argumentation, and they can call upon - or easily find - a body of knowledge for their writing topics. What most of our target group lack is awareness of their instructors as audience. In consequence, their appreciation of the genres they will need to command tends to be limited to technical matters such as the need for references. Perhaps above all, they rarely perceive, in their first semesters at graduate school, the extent to which the academic texts they read and write are negotiated and strategic. Most specifically, they only dimly recognize that their own textual products are being continually scrutinized for evidence of growing academic maturity and successful disciplinary apprenticeship.

If Academic Writing for Graduate Students (henceforth, AWG) has in part evolved out of our perceptions of what being a beginning graduate student writer involves, it equally emerges from the pragmatics of our recent teaching experiences. If the perceptions represent a nascent "vision" or "theory" (motivation 2), then the pragmatics represent a sense that it was "time to do something about" several years' worth of teaching materials for a range of academic writing courses (motivation 1). At first sight, the relationship between the course materials and the book looks simple and straightforward. At the University of Michigan, the English Language Institute (ELI) currently offers four levels of writing courses for NNS graduate students (20-25 contact hours each and each worth one or two credits): ELI 320 (Academic Writing I); ELI 321 (Academic Writing II); ELI 520 (Research Paper Writing; and ELI 600 (Prospectus and Dissertation Writing). Ideally, a student would take 320 and 321 in her first year, 520 in her second or third, and 600 in her fourth or fifth. The way these materials were "massaged" into the book is summarized in Table 1 (the appendices have been excluded).

The table, however, disguises the complexities and intertextualities of the process. Despite some previous experience in the area, I found myself having to learn once again that course materials and textbooks are very different 
TABLE 1

Origins of AWG

\begin{tabular}{ll}
\multicolumn{1}{c}{ Units } & Sources \\
\hline 1 - Introduction & ELI 320 \\
$2-$ General-Specific Texts & ELI 320 \\
3 - Problem-Solution Texts & ELI 320 \\
$4-$ Data Comnuentaries & ELI 320 \\
$5-$ Summary Writing & ELI 321 \\
6 - Writing Critiques & ELI 321 \\
7 - Constructing a Research Paper I & ELI 520 \\
$8-$ Constructing a Research Paper II & ELI 520 \\
\hline
\end{tabular}

genres - as different as class lectures and conference presentations. Course materials (whether your own or created by close colleagues), are based on the assumption that the instructor has an inside track on what is going on and why. Time and again, Chris Feak and I revised and re-revised in order to try and produce something manageable for an instructor from a different "educational culture" and with a different history of teaching experiences. Further, the "materials history" of AWG is more elaborate than Table 1 intimates. For example, the groundwork for Unit One is actually the writing section of Williams et al. (1984), while fragments of the book, particularly in Unit Four, go back as far as Writing Scientific English (1971). (The copyright was returned to me several years ago.)

So far, I have illustrated the first and second of the six motivations for AWG. I would not like to comment briefly on numbers 5 and 6 , leaving more space for the two research-driven motivations. Like many ESP practitioners, I derive much personal satisfaction from attempting to be - and to be seen as - an all-rounder. So, it naturally occurred to me that the story told in Genre Analysis (1990) lacked one kind of closure by not having its counterpart in the textbook genre. As it happens, this is not quite what AWG is, since the matched counterpart would have presumably begun with, say, the last three units and then gone further into the research world from there. One of the reasons for the eventually more oblique relationship comes from the need to balance and fully utilize two people's teaching experiences. Another derives from the exigencies of planning and ESP textbook series for the University of Michigan Press. What is the sense, after all, in producing Volume II before Volume I?

Part of any textbook planning stage naturally involves assessing the "competition" on the market, seeing whether there is indeed a niche to be filled and, if so, estimating "shelf-life" (motivation 6). We identified two recent volumes that we needed to take particular account of. One was Writing up Research by Weissberg and Buker (1990). This is a useful volume, which has on occasion been used in the institute's classes. However, Weissberg and Buker adopt a technical approach to academic writing with a strong emphasis on the more straightforward aspects of prescnting rescarch data. While wc thought that AWG might emerge as similar in length and amount of exposition, we felt it would be very different in tone and orientation, particularly since our emphasis 
would be on how graduate students can "position themselves" as junior members of their chosen discourse communities. The other volume was the second edition of Huckin and Olsen's Technical Writing and Professional Communication for Nonnative Speakers of English (1991). This also is an impressive volume: large, comprehensive, almost encyclopedic, and full of the kind of careful exposition that a useful handbook requires. We felt, however, that it focused more on technical than academic communications and, while rhetorical and functional in orientation, would differ radically from AWG in the way it engaged students in rhetorical tasks. We felt we could argue that Weissberg \& Buker and Huckin \& Olsen would be complementary rather than competitive.

\section{Countering Low Research Expectations}

There are a number of measures that can be taken to blur the over-sharp boundary between research papers and textbooks. Although some of these measures might be incongruous in teaching materials designed for beginners or children, I believe they find a natural home in EAP textbooks. First, like Huckin and Olsen, AWG has the apparatus of a scholarly work. There is an index, a select list of references at the end, and light use of citations in the expository sections of the text itself. Second, we have not tried to hide the fact that the research base is stronger in some areas than in others; on the contrary, we advertise, as part of an ongoing dialogue, areas of uncertainty. Third, on several occasions, we invite the students to carry out small-scale surveys of rhetorical and linguistic practices in their own fields. We do this in part as a consequence of our belief in the value of rhetorical consciousness-raising - at least for this elite group of students - and in part because it is a way of coping with disciplinary variation. The following extract from Unit 7 illustrates this approach:

\section{Commentary in Results Sections}

It is often said that the results section of an RP should simply report the data that has been collected; that is, it should focus exclusively on the present results. Indeed, many of the books and manuals aiming at helping students and scholars to write research papers offer this kind of advice. These books argue, particularly, that all evaluation and commentary should be left until the Discussion. However, research shows that this distinction between Results and Discussion is not as sharp as commonly believed. For example, Thompson (1993) studied the Results sections from 20 published Biochemistry papers. This is what she found:

[Table of commentary elements - not given here]

This is part of Thompson's conclusions:

My research demonstrates that scientists - in this case biochemists - do not present results only in a factual expository manner; they also employ a variety of rhetorical moves to argue for the validity of scientific facts and knowledge claims. (p. 126)

Authors often include commentary because they are aware of their audience. They can anticipate that their readers may be thinking "Why did they use this 
method rather than that one?" or "Isn't this result rather strange?". For obvious reasons, authors may not want to postpone responding to such imaginary questions and critical comments until the final section.

\section{Task Nine}

Take two Results sections (one you have written or one from your field, the other our draft on sentence-connectors). Read them carefully, marking any commentary elements. In your estimation, are the passages most like:

[Chart summarizing four types of results section in terms of amount of commentary - not given here]

Be prepared to discuss your findings in class. Bring your first passage with you.

A fourth way we have used to blur the boundaries is to incorporate a small research project of our own into the textbook. We wanted a project that dealt with Academic English, because concern about this was something shared by all participants, and because such a project would clearly fall within the specialized expertise of instructors. We wanted it to be quantitative, but not statistical. We even wanted it to be somewhat unimpressive and unimportant, so that student research projects would have an excellent chance of outshining ours. What we came up with can be seen from this extract from our draft Methods sections:

\footnotetext{
Methods

In order to investigate the position of connectors, we examined their occurrence in academic papers published in three journals. The sample consisted of all the main articles appearing in the third issues of the 1992 volumes of College Composition and Communication, English for Specific Purposes, and Research in the Teaching of English. (See Appendix A for a list of the articles studied). The sample amounted to about 230 running pages of text, comprising 12 articles (four from each journal). Each occurrence of a connector was identified, highlighted and then coded for one of three positions in a clause. If the connector was the first or last word in the clause it was designated "initial" or "final" respectively. If it occurred in any other position it was classified as "medial". The following examples illustrate the coding system: ... .
}

Overall, as I hope the extracts have communicated, we have taken pains to ensure that AWG - for all its undoubted weaknesses - "looks like" a careful scholarly product. We have fought against any tendency to make AWG an example of "canonizing discourse" in the traditional textbook sense. We have tried to establish in the minds of both reader-evaluators and reader-consumers that Academic Writing for Graduate Students is itself "academic."

\section{Using the Research of Others}

Another feature - and motivation - of Academic Writing for Graduate Students is the attempt to integrate and incorporate contemporary research of various kinds. As this is a potentially extensive topic, I will restrict my comments to two aspects of Unit 4 (Data Commentaries). I have chosen Unit 4 partly because it is the crucial "hinge" unit which attempts to link the prepa- 
ratory work of the preceding units with the more genre-specific writing of the subsequent ones. As it happens, over the last 2 years or so, the ELI Testing Division has been developing a new graduate-only placement test entitled "Graduate Test in Academic Skills in English" or "GTASE" (Kunnan \& Dobson 1993). Prototype materials include two writing tasks: a recommendation letter and a data commentary. Data commentaries are assessed on a four-point scale. Below is the descriptor of the third level (i.e., next to best):

Task is, generally speaking, completed. More than a mere translation of the table - there is some classification, or summary, or restatement paraphrasing of the data and some attempt at appropriate commentary/interpretation. Still, there is often too much repetition of the table. If the conflicting data . . . is mentioned, there is some attempt to explain it in the context of other data. Organization is satisfactory. Style/register is not inappropriate (if problems exist, they are likely to be sins of omission rather than commission).

In fact, the development of these elaborate descriptors proceeded in parallel with the evolution of the data-commentary textbook unit. The authors and test-developers exchanged ideas, writing samples, test/assignment items and gleanings from the literature with each other over a period of months. Although there was never a conscious plan to collaborate in this way, it turned out that two independent R \& D processes became linked in a highly synergistic manner, again pointing to the complexities of textbook origination.

As the example shows, the descriptors assess success or failure in the task in terms of "impression management" or, more precisely, in terms of how well the writer is able to position herself as a credible academic commentator and interpreter. It is not coincidental that major research projects on writing success also tend to stress the need for the writer to detach herself from the point of utterance and from the confines of introspective cognition. Well known examples are Flower and Hayes (1981) on the advantage of moving from "writer-based" prose to "reader-based" prose and Bereiter and Scardamalia (1987) on the need to expand "rhetorical working space." We build upon this research in order to enable our students to become more proactive in their perceptions of their instructor audience.

The next extract is part of Task Ten from Unit 4. Task Ten opens with a table giving figures for "years to doctorate" for various groups of students, including domestic and international ones at the University of Michigan. Students are then asked to read a six-sentence draft commentary (not shown here) and carry out the task which follows:

Here are the instructor's comments on the above commentary. The instructor is a professor of Comparative Higher Education. Discuss in pairs whether you think the comments arc reasonable (R) or unrcasonable (U). If you find some reasonable, how would you edit the passage? There are no absolutely right or wrong answers here.

a) In sentences 2, 3 and 4 you throw away the key finding that more rapid progress to degree and high completion rates is consistently in favor of international students across all six divisions. You need to highlight this more. 
b) You need to stress that based on present knowledge we can only speculate about the explanations. As it stands I find S5 hard to interpret. Is this just your idea, or do you have any evidence for this claim? c) It is strange that you don't mention the English language factor. At least at first sight, this would seem to suggest that international students ought to be taking longer.

d) Don't you think you ought to finish by suggesting ways of getting at the real causes of this striking phenomenon? Case studies? Interviews with faculty and students?

As might be expected, the data underlying this task is very appealing to international students. More importantly, however, it asks the class to confront the tricky problem of what to do when the instructor makes unhelpful (as well as helpful) comments and suggestions on students' work. 'Task Ten is thus interactive and intertextual, and illustrates well our efforts in AWG to become a rhetorical voice in the students' heads.

\section{Textbooks and the Generation of Research}

One of the challenges of textbook writing is that it demands appropriate coverage of the field. The textbook writer, unlike the scholar and researcher, has less freedom to concentrate on the "best" data. In textbooks, the need for adequate coverage of the material leads on occasion to having to say something about apparently "inexplicable" phenomena (generic article usage?), or patterns of organization "resistant" to analysis (discussion sections?). In the latter case, for example, we make in Unit 8 a good-faith effort to be helpful by moving away from the "move analysis" tradition in this area (e.g., Hopkins \& DudleyEvans 1988). Inspired by Mauranen (1992) and by the Olsen and Huckin paper on "Point-driven Understanding in Engineering Lecture Comprehension" (1990), we have opted instead for a concept of Discussion as constructed out of a semi-ordered list of "points." Also, in Unit 8, we have incorporated findings from a structural analysis of Acknowledgments. Here is the resultant summary:

b) As far as we can see, Financial Support tends to come first, followed by Thanks. Disclaimers seem optional. Other Version and Source (if used) seem to come either at the beginning or at the end. (But note that in theses and dissertations, it is customary to open with thanks to supervisors, advisors, and committee-members).

If the above two illustrations might be seen as making their own small contributions to the database on research discourse in English, it is equally important to realize that the textbook-writing process - through the coverage requirement - itself raises as many questions as it answers. Again, there is only space for two small examples. A partial analysis of research paper abstracts showed some findings that need further testing (cf. Ventola 1993). Among these were (a) wide use of "we" plus the Present Tense in Physical Science 
abstracts, especially in Astrophysics (cf. Tarone, Dwyer, Gillette, \& Icke 1981); and (b) a surprising amount of the very limited space being given over to introductory or "field-establishment" concerns in many abstracts. Accordingly, a study has recently been completed to gain more information on these and other characteristics of abstracts (Melander, Swales, \& Fredrickson 1994).

The second example of a discourse analysis project arising from the textbook process concerns imperatives in academic and research English. According to Politeness Theory (e.g., Myers 1989), in peer-to-peer contexts imperatives look like "face-threatening acts." Yet they seem to occur, if rarely and with severe lexical restraints:

Recall that Jones had originally found. . .

? Remember that Jones had originally found . . .

* Don't forget that Jones had originally found . . .

A project is planned on this topic too.

\section{Conclusion: Textbooks as Hybrid Genres}

With the foregoing, I have tried to establish that textbooks can be more complex in their origins and aspirations than either the available discourse analyses of introductory textbooks suggest or the prevailing attitudes in the academy are willing to admit. Post-introductory textbooks are not so much "blurred" in Geertz's sense of odd combinations of subject matters and rhetorics, but "hybrid" in their efforts to cope with a complex audience configuration, to represent a broad area of available knowledge, to offer a "vision," and to incorporate new findings emerging as a result of the exigences of textbook writing.

Of course, these hybrids are likely to vary according to whether they teach practices and skills, such as AWG, or whether, as is more typical, they teach a structure of knowledge. In either case, though, they soften the hard line typically drawn between research articles and monographs, on the one hand, and basic textbooks, on the other. Important instances of these hybrids, such as the Cambridge "red" textbook series in Linguistics, need urgent attention, so that we can better see how such volumes construct specialist fields both for other specialists and for apprentices. Comparison with work in other areas such as Myers' (1990) study of semi-popularizations in science would be a further benefit.

More narrowly, in this paper I have taken on the task of promoting textbooks in our fields as being at least in some cases - descrving mombcrs of the academic genre-system. Indeed, through chapter and verse, I have tried to suggest that they belong in the system not on sufferance, but because they potentially create a unique kind of synergy which links theory to practice, past and present research to the future, task to text, and local initiative to the wider development of the field. Admittedly, my arguments have often taken on the 
character of special pleading from a case in which I have a personal stake. On the other hand, I have a special and personal apology to make. In Genre Analysis (pp. 177-78) I presented a map and offered a general discussion of research-process genres. The account presented there was incomplete and somewhat misleading. It failed to do justice to the major struggles most people experience in shifting material from one genre to another. Two well-known cases are turning well-formed oral presentations into well-formed research articles and transforming dissertations into books. Another failure was to focus exclusively on the public genres and to ignore the interstitial genres (proposals, reader's reports, editorial correspondence, etc.) which have a major role in shaping both the process and the final public product. Most germanely to this paper, however, at that time and in that mind-set I wrote the textbook completely out of the picture of research-process genres. With considerably less intellectual arrogance, I have, in this piece, tried to put it back in.

Acknowledgements - My biggest debt is to Christine Feak, without whose collaboration AWG would not now be in press. I would also like to thank her, Barbara Dobson, Kirstin Fredrickson, and the main anonymous reviewer for helpful comments on earlier versions of this paper.

(Revised version received July 1994)

\section{References}

Alred, G. A., \& Thelen, E. A. (1993). Are textbooks contributions to scholarship? College Composition and Communicalion, 44, 466-477.

Bakhtin, M. M. (1986). Speech genres and other late essays. Austin, TX: University of Texas Press.

Bazerman, C. (1992). The generic performance of ownership: The patent claim and grant. Paper presented at the Re-Thinking Genre Seminar, Carleton University, Ottawa, April 1992.

Bereiter, C., \& Scardamalia, M. (1987). The psychology of written composition. Hillsdale, NJ: Erlbaum.

Brown, V. (1993). Decanonizing discourses: Textual analysis and the history of economic thought. In W. Henderson, T. Dudley-Evans, \& R. Backhouse (Eds.), Economics and language (pp. 64-84). London: Routledge.

Flower, L., \& Hayes, J. R. (1981). A cognitive theory of writing. College Composition and Communication, 32, 365-387.

Gebhardt, R. C. (1993). Scholarship, promotion and tenure in composition studies. College Composition and Communication, 44, 439-442.

Geertz, C. (1983). Local knowledge: Further essays in interpretive anthropology. New York: Basic Books.

Henderson, W., \& Hewings, A. (1990). Language and model building. In A. Dudley-Evans \& W. Henderson (Eds.), The language of economics: The analysis of economics discourse (pp. 43-54). ELT Documents 134. London: Modern English Publications.

Hewings, A. (1990). Aspects of the language of economics textbooks. In A. Dudley-Evans \& W. Henderson (Eds.), The language of economics: The 
analysis of economic discourse (pp. 109-127). ELT Documents 134, London: Modern English Publications.

Hopkins, A., \& Dudley-Evans, T. (1988). A genre-based investigation of the discussion sections in articles and dissertations. English for Specific Purposes, 7, 113-122.

Huckin, T. N., \& Olsen, L. A. (1991). Technical writing and professional communication for nonnative speakers of English. New York: McGraw-Hill.

Kuhn, T. N. (1970). The structure of scientific revolutions (2nd ed.). Chicago: The University of Chicago Press.

Kunnan, A., \& Dobson, B. (1993). Standard setting and cut scores in an ESL test: The GTASE experience. Paper presented at RP-ALLA, Columbus, OH, November, 1993.

Love, A. M. (1991). Process and product in geology: An investigation of some discourse features of two introductory textbooks. English for Specific Purposes, 10, 89-109.

Love, A. M. (1993). Lexico-grammatical features of geology textbooks: Process and product revisited. English for Specific Purposes, 12, 197-218.

Mason, M. (1990). Dancing on air: Analysis of a passage from an economics textbook. In A. Dudley-Evans \& W. Henderson (Eds.), The language of economics: The analysis of economic discourse (pp. 16-28). ELT Documents 134. London: Modern English Publications.

Mauranen, M. (1992). Cultural differences in academic rhetoric: A textlinguistic study. unpublished $\mathrm{PhD}$ thesis, The University of Birmingham, UK.

McCloskey, D. N. (1985). The rhetoric of economics. Madison, WI: The University of Wisconsin Press.

Melander, B., Swales, J. M., \& Fredrickson, K. (1994). Journal abstracts from three academic fields in the United States and Sweden: National or disciplinary proclivities? (mimeo).

Myers, G. (1989). The pragmatics of politeness in scientific articles. Applied Linguistics, 10, 1-35.

Myers, G. (1990). Writing biology. Madison, WI: The University of Wisconsin Press.

Myers, G. (1992). Textbooks and the sociology of scientific knowledge. English for Specific Purposes, 11, 3-17.

Olsen, L. A., \& Huckin, T. N. (1990). Point-driven understanding in Engineering lecture comprehension. English for Specific Purposes, 9, 33-49.

Phillips, D. B., Greenberg, R., \& Gibson, S. (1993). Chronicling a discipline's genesis. College Composition and Communication, 44, 443-465.

Robinson, P. (1991). The ESP practitioner. Oxford: Pergamon.

Swales, J. (1971). Writing scientific English. Sunbury, UK: Thomas Nelson.

Swales, J. (1980). ESP - The textbook problem. English for Specific Purposes (ESPJ), 1, 11-23.

Swales, J. M. (1988). Twenty years of TESOL Quarterly. TESOL Quarterly, $22,151-163$.

Swales, J. M. (1990). Genre analysis: English in academic and research settings. Cambridge, UK: Cambridge University Press. 
Swales, J. M. (1993a). The paradox of value: Six treatments in search of the reader. In W. Henderson, T. Dudley-Evans, \& R. Backhouse (Eds.), Economics and language (pp. 223-239). London: Routledge.

Swales, J. M. (1993b). Genre and engagement. La Revue Belge de la Philologie et L'Histoire.

Swales, J. M. (in press). English for academic purposes. In P. Byrd (Eds.), Writing for publication. Boston: Heinle \& Heinle.

Swales, J. M., \& Feak, C. B. (1994). Academic writing for graduate students: Essential tasks and skills. Ann Arbor, MI: The University of Michigan Press.

Tadros, A. (1985). Prediction in text. Birmingham, UK: The University of Birmingham, English Language Research.

Tarone, E., Dwyer, S., Gillette, S., \& Icke, V. (1981). On the use of the passive in two astrophysics journal papers. English for Specific Purposes (ESPJ), 1, 123-140.

Thompson, D. K. (1993). Arguing for experimental "facts" in science. Written Communication, 8, 106-128.

Ventola, E. (1993). From syntax to text - Problems in producing scientific abstracts in L2. In S. Cmerjrkova \& F. Sticha (Eds.), The syntax of sentence and text: A festschrift for Frantisek Danes on his 75th birthday. Amsterdam: John Benjamin.

Weissberg, R., \& Buker, S. (1990). Writing up research. Englewood Cliffs, NJ: Prentice-Hall, Regents.

Williams, R., Ray, R., Swales, J. (1984). Communication in English for technical students. Calcutta: Longman Orient.

John M. Swales is Director of the English Language Institute and Professor of Linguistics at the University of Michigan, Ann Arbor. He has published widely on ESP and on the nature of academic writing. 